\title{
Surface integrity after post processing of EDM processed Inconel 718 shaft
}

\author{
Jonas Holmberg $^{1,2}$ • Anders Wretland ${ }^{3}$. Johan Berglund ${ }^{1} \cdot$ Tomas Beno $^{2}$
}

Received: 3 July 2017 / Accepted: 7 November 2017 / Published online: 22 November 2017

(C) The Author(s) 2017. This article is an open access publication

\begin{abstract}
Electrical discharge machining (EDM) is considered as an efficient alternative to conventional material removal concepts that allows for much higher material removal rates. However, EDM generates unwanted features such as re-cast layer (RCL), tensile residual stresses and a rough surface. In order to recover the surface integrity, different post processes has been compared: high-pressure water jet (HPWJ), grit blasting (GB) and shot peening (SP). Surface integrity has been evaluated regarding microstructure, residual stresses, chemical content and surface roughness. The results showed that a combination of two post processes is required in order to restore an EDM processed surface of discontinuous islands of RCL. HPWJ was superior for removing RCL closely followed by grit blasting. However, grit blasting showed embedded grit blasting abrasive into the surface. Regarding surface roughness, it was shown that both grit blasting and HPWJ caused a roughening of the surface topography while shot peening generates a comparably smoother surface. All three post processes showed compressive residual stresses in the surface where shot peening generated the highest amplitude and penetration depths. However, the microstructure close to the surface revealed that shot peening had generated cracks parallel to the surface. The results strongly state how important it is to evaluate the surface at each of the different subsequent process steps in order to avoid initiation of cracks.
\end{abstract}

Jonas Holmberg

jonas.holmberg@swerea.se

\footnotetext{
Manufacturing, Swerea IVF AB, Mölndal, Sweden

Engineering Science, University West, Trollhättan, Sweden

3 GKN Aerospace Sweden AB, Trollhättan, Sweden
}

Keywords Surface integrity · Inconel 718 - Shot peening · Abrasive water jet $\cdot$ Grit blasting $\cdot$ EDM

\section{Introduction}

\subsection{Traditional machining concepts}

There is a strong demand for improved material removal rates (MRRs) in the production of aero-space engine components. This is both due to the challenging properties of the alloys these components are made of, and also because of industry reasons; the demand for a clean and efficient air transport system has never been as high as it is today, as stated in the European aviation environmental report [1].

The typical aero engine part is designed for low weight, high durability and strength. To avoid any detrimental impact from edge or border effects, the raw material is most often designed and formed with a substantial allowance for the final shape $[2,3]$. The demand for an efficient material removal process is therefore obvious. However, not so obvious are the alternatives to the traditional material removal concepts of which conventional machining is the most commonly used.

The traditional means to remove large amounts of material is high speed rough milling with ceramic tools followed by milling with WC inserts. In recent years, WC insert milling is frequently assisted by high-pressure coolant application to achieve an even further improved level of productivity, explored, e.g. by Ezugwu et al. [4]. As such, development of the milling process of difficult to machine materials has either focused on improving the properties of the insert tool material to withstand the cutting conditions or to increase the cutting speeds [5]. Development has also been devoted to improve the heat dissipation in the cutting zone by redesign of insert geometry and thereby enabling increased MRR [6]. 
However, in order to further increase the material removal rate for these materials, new and non-conventional high-energy machining methods become increasingly interesting to evaluate as alternatives. In particular, since the removed material sometimes can be used to manufacture smaller parts instead of being turned into chips.

\subsection{High energy material removal methods}

High energy material removal methods allow the machining process to take a major leap to increase the removal rate. However, these methods also have a significant impact on the part integrity as they alter the state of the surface after processing by the introduction of defects or surface residuals, generate unfavourable tensile residual stresses or influence the surface roughness.

Abrasive water jet machining (AWJM), laser beam machining (LBM) and electrical discharge machining (EDM) are examples of such high energy impact methods, all of which are considered as non-conventional and are only used to a limited proportion in production today. These methods will in various degrees alter the properties of the component and will often generate unwanted residues on the surface that needs to be addressed by some applicable post processing method.

In the present study, EDM processed surfaces were selected for investigation due to the process' ability to remove large amounts of material into rather complex geometries. Further, this method is the only non-conventional machining alternative used to some extent in the production of aero-space engine production today [7]. EDM utilises heat in order to melt and cut the material and since this processing is performed where the part is immersed in water, the extension of the surface alteration is limited to the outermost surface $[8,9]$.

\subsection{Part integrity}

\subsubsection{General notions}

Aero-space engine components have requirements both regarding geometry and surface integrity. The important surface integrity aspects for these components are surface topography, microstructure, and residual stresses. In order for any of these non-conventional methods to get acceptance and to be used in production, the generated surface needs to meet the individual surface integrity requirements. This set of requirements is commonly set by what is regarded as "gentle machining", which typically corresponds to a finish milled surface. A fine-milled surface is typically machined using small depth of cut, low cutting speed and feed [10]. Finish milling often only relates to optimising the topography, for example explored by Elbestawi et al. who investigated end milling of a AISI 1020 steel [11]. However, the finish machined surface is of great importance in other aspects as well since it sets the final surface quality related to residual stresses, hardness and alterations in the microstructure. As mentioned by Sar" et al., the cutting parameters, cutting speed and feed need to be optimised for a finish milling operation [12].

In order to guarantee that the finish milled surfaces meet the specifications, post processing by shot peening is frequently employed. This method has the ability to affect both the surface topography and residual stresses in order to secure the component's fatigue strength [9]. Further, to recover the surface integrity of a non-conventionally machined surface to the same level as one generated by means of a conventional machining, it is probable that post processing is required using one or several methods.

In order to obtain this, there are several available post processing methods with different possibilities and applications. These methods could be categorised into cold-working methods, chemical methods and heat treatment (thermal) methods. In this investigation, only cold-working methods were considered because the aim is to find a method that could address the issue regarding re-cast layer as well as introducing compressive residual stresses to the surface. Even though an interesting approach was suggested by Wang et al. involving chemical etching and brushing, this method will not generate compressive stresses [10]. Heat treatment as a post process will always be performed for this kind of material in the end of the production, but this has not been a part of this investigation.

Further, cold-working methods offer greater possibilities to influence the material's properties, such as residual stresses, by alteration of the process parameters (type of medium, geometry of medium, velocity of medium, etc.). For this reason, three post processes that each can present a substantial mechanical impact on the surface were considered for further investigation.

The selected methods, grit blast, shot peen and highpressure water jet clean, were explored in terms of their ability to generate a surface free from re-cast layer and with compressive residual stress distribution. The influence on surface integrity from these three post processes has been described separately for each method in several papers.

\subsubsection{Abrasive water jet peening and cleaning}

Lately, a lot of attention has been paid to high-pressure water jet methods, describing, among other things, the method as means for cleaning and its cleaning capabilities [13, 14]. This is basically a method where a conventional water jet cutting beam is used to clean the surface but without any abrasive particles. When the water jet strikes the surface, an erosion process takes place which results in material removal. The water jet cutting technology has been developed during the past 20 years and a lot of attention has been paid to investigate 
the water jet beam by simulations $[15,16]$. A frequently reported theme in the literature involves how to set the machining parameters in order to create a straight cut and diminish the kerf that is created at the AWJ inlet [17]. In addition, several papers describe the more theoretical aspects of the water jet cleaning process including Guha et al., who presented an experimental and numerical study of the built-up pressure from the water jet beam which shows the importance of assessing the pressure distribution on the surface to be cleaned, in order to optimise the removal rates for cleaning [13]. That investigation included an evaluation of the water jet beam with different beam diameters and water jet pressures. The results showed that there is no cleaning of the surface at positions located $1.68 \times$ beam diameter (D), in the test equal to approximately $12.1 \mathrm{~mm}$ in diameter, from the centre line of the water jet beam. Further, it was shown that the stand-off distance between the nozzle and surface to be processed should be kept between 5 and $26 \times \mathrm{D}$ in order to clean the surface.

The industrial aspect of using the water jet method has historically mainly been within the medical industry used for titanium alloys. The main object of that research has been devoted to investigate the method's ability to clean the surface and to generate a roughening of the surface that is needed for medical implants to improve the implant's ability to adhere to the human bone. On this subject, Barriuso et al. considered water jet as a cleaning method for medical implants and studied the roughening effect for titanium alloys [18]. Further, the influence on the fatigue strength after post processing of Ti6A14V samples was reported by Lieblich et al. [19]. These results showed that blasting with alumina oxide particles was less harmful for fatigue resistance than water jet peening, even though there is a risk of embedded $\mathrm{Al}_{2} \mathrm{O}_{3}$ particles acting as nucleation points for cracks. It was further shown that the water jet pressure had a strong influence on the fatigue limit of the material where a lower pressure was preferable. The reason for the results was believed to be related to the surface roughness that increases with increased water jet pressure. Further work within this field has been performed by Sadasivam et al., who investigated the abrasive water jet peening concept to be used as an approach to develop a rough surface with beneficial compressive residual stresses for Ti6Al4V [20]. In this study, the abrasive alumina oxide particles were used to peen the surface and in order to increase the compressive stresses, a pre-strain was used. This pre-strain was obtained by bending the samples in a four-point bending fixture. It was shown that the surface residual stresses increased with increased pre-stress level.

Another interesting possibility with the abrasive water jet method is that it could be used both as a machining method but also as a post process to clean or to generate a desired surface texture. This means that the machining and post processing could be done in one and the same machine in a sequence. This type of hybrid concept was evaluated by
Huang et al. who showed that abrasive water jet machining could be performed to a near desired depth followed by the cleaning in a second step without the abrasives [21]. The concept showed great potential to be used to clean quite thick layers of alpha cases for Ti6Al4V. It was further shown that the parameters of the water jet cleaning played an important role in removing the abrasive grit from the previous water jet cutting process.

\subsubsection{Grit blasting and shot peening}

Grit blasting and shot peening are alternative cold-working post processes, which are well-established methods where the prior is used for cleaning. However, there is a lot of industrial information available concerning grit blasting but only limited published scientific information on how the process influences the surface. The influence of particle velocity, or rather the air pressure, was explored by Khan et al. who investigated the resin adhesion properties to a titanium sheet of the blasted surface exposed to long-time water ageing [22]. It was found that the highest air pressure resulted in the highest surface roughness and thereby promoted the adhesion strength in long-term water ageing. The only available results concerning grit blasting of Inconel 718 was reported by the authors in the present investigation from tests performed evaluating grit-blasting parameters on a forged EDM shaft Inconel 718. These results showed the influence of stand-off distance and exposure time on the surface integrity; the erosion increased with exposure time resulting in an increased removal of RCL [23].

On the contrary, shot peening is instead mainly used to generate compressive residual stresses or to generate a specific surface topography and the possibilities for removing RCL have not yet been reported. The surface integrity and fatigue properties are greatly affected by the selection of shot peening parameters which, according to literature, mainly are velocity of the shot, size and hardness of the shot [24, 25]. Koster et al. reported not only that shot peening generated an improved fatigue life of three times for Inconel 718 but also that the material properties at elevated temperatures up to $810 \mathrm{~K}$ was extended due to the shot peening operation of EDM Inconel 718 fatigue specimens [26]. However, that investigation did not describe any details regarding the initial state of the material which also may have great influence on the result. There is other related work done on shot peening of Inconel 718, but these are mainly focusing on the relaxation of the compressive residual stresses at elevated temperatures $[27,28]$.

\subsubsection{The scope of the present investigation}

In the present investigation, grit blasting, shot peening and high-pressure water jet cleaning were compared in order to find the most suitable process to recover the surface integrity 
Table 1 Chemical composition of the sample shaft

\begin{tabular}{llllllllllllllllllllllll}
\hline Element $[w t-\%]$ & $\mathrm{C}$ & $\mathrm{S}$ & $\mathrm{Mn}$ & $\mathrm{Si}$ & $\mathrm{Cr}$ & $\mathrm{Mo}$ & $\mathrm{Co}$ & $\mathrm{Ti}$ & $\mathrm{Al}$ & $\mathrm{B}$ & $\mathrm{Zr}$ & $\mathrm{Fe}$ & $\mathrm{Cu}$ & $\mathrm{Ni}$ & $\mathrm{P}$ & $\mathrm{Nb}$ & $\mathrm{Ta}$ & $\mathrm{W}$ & $\mathrm{V}$ \\
\hline As received & 0.024 & $<0.0003$ & 0.65 & 0.7 & 17.96 & 2.89 & 0.23 & 0.99 & 0.48 & 0.0036 & $<0.01$ & Bal. & 0.04 & 53.9 & 0.0095 & 5.21 & $<0.01$ & 0.02 & 0.03 \\
\hline
\end{tabular}

of an EDM-processed Inconel 718 surface. These are three well-established cold-working post processes, and the most essential requirement to be addressed for an EDM surface is to completely remove the re-cast layer.

However, there is a knowledge gap in the literature of explaining the surface integrity aspects after post processing nickel-based aero-space super alloys. Separate parametric studies can be found in the literature mainly regarding shot peening. These results describe the effect of the process from simulations, but the influence on the surface integrity has only been evaluated to a limited extent. Correspondingly, for abrasive water jet cleaning and grit blasting, only limited reports has been presented for nickel-based alloys. Hence, the present investigation and comparison was performed with the objective, to some extent, to fill this identified knowledge gap.

The main objective with this work has been to compare the mentioned post processes in order to generate relevant input data for the definition of an alternative manufacturing process chain where the first removal step is EDM. The aim of the study is to clarify how the individual process steps will influence the surface integrity to reach a surface condition after the final operation that is on par with a similar material removal operation based on conventional machining methods.

\section{Method}

\subsection{Material}

All test samples were taken from a shaft of Inconel with the chemical specification shown in Table 1. The shaft was produced in an open die forging followed by heat treatment. The heat treatment used a solution annealing at $975^{\circ} \mathrm{C}$ for $60 \mathrm{~min}$ followed by quenching in a polymer. The ageing was done in two temperature steps followed by cooling in air. The resulting hardness of the shaft was $261 \mathrm{HB}$ after forging and $432 \mathrm{HB}$ on the final heat-treated part.

\subsection{Experimental set up}

The test samples for these investigations were taken from a shaft that has been manufactured using industrial best practice machining parameters. The machining steps for this component involve wire-EDM processing to a near net shape with the parameters shown in Table 2. After EDM, the surface had a typical appearance according to Fig. 1, showing the relatively discontinuous re-cast layer.

The EDM shaft was further sectioned into several samples shown in Fig. 2, where the post processing using grit blasting, shot peening, water jet cleaning and combinations of the three processes was performed.

In prior investigations conducted by the authors, the grit-blasting process' ability to remove RCL was evaluated by testing different exposure times and nozzle standoff distances [23]. The grit-blasting parameters resulting in the lowest amount of RCL residue and highest compressive residual stress level were selected for the present study.

The prior investigation also described a suitable method to determine whether the RCL has been removed from the surface by measuring the chemical content on the surface. A similar approach for evaluating the surface after the different post processes was employed in the present investigations.

\subsubsection{Grit blasting}

The grit-blasting operation was performed in a robot cell where the sample was mounted on a turntable and the blast nozzle held by the robot in order to achieve a fully repeatable set up. The robot motion during the blast operation was single axis only, parallel to the shaft where the attack of the stream of blast media was perpendicular to the shaft during all of the tests. The following grit-blasting parameters were selected: a 25-mm nozzle distance, a 40-s exposure time, using aluminium oxide particles as grit-blasting media with a grit size of $60 \mu \mathrm{m}$ and a 4-bar pressure of the media.

Table 2 EDM processing parameters

\begin{tabular}{ll}
\hline Parameter & Setting \\
\hline Machine & Sodik AQ400L \\
Cutting speed & $0.36 \mathrm{~mm} / \mathrm{min}$ \\
Wire diameter & $0.25 \mathrm{~mm}$ \\
Wire brand & Bedra megacut ${ }^{p}$ plus \\
Wire composition & CuZn36, $\gamma$-messing coating \\
Nozzle gap & $0.1 \mathrm{~mm}$ \\
Nozzle diameter & $6.5 \mathrm{~mm}$ \\
Wire feed & 15 (setting of the machine) \\
Tank medium & Dieletric water \\
\hline
\end{tabular}


Fig. 1 Micrograph of an etched cross section of an EDM:ed surface. a In $\times 200$ magnification. b In $\times 1250$ magnification
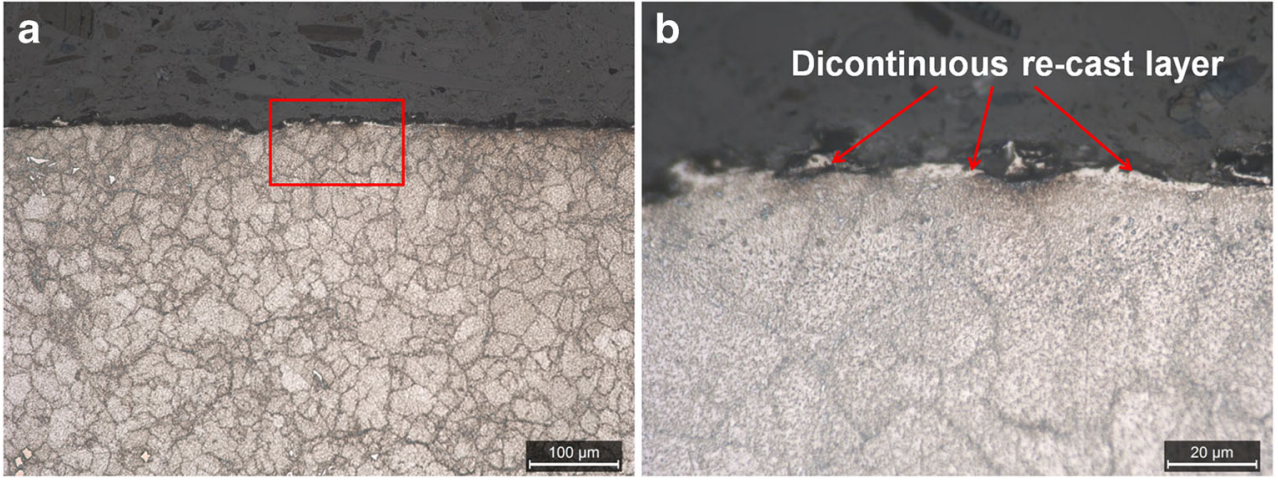

\subsubsection{Shot peening}

The shot peening was performed in a CNC-operated shot peening cell using a perpendicular attack angle of the medium and a nozzle distance of $100 \mathrm{~mm}$. The shot peening intensity was $0.165 \mathrm{~A}$, where A refers to the Almen test strip shape. The shot peening media was Cutwire 14 and the pressure during the test was 3 bar. The selected shot peening parameters are considered as best practice parameters for this application and were derived from an Almen stripe testing for this type of material and geometry in order to attain complete shot peening coverage.

\subsubsection{High-pressure water jet}

The high-pressure water jet operation was performed in a CNC-operated water jet cutting machine using $360 \mathrm{MPa}$ in water pressure. The stand-off distance, distance between the nozzle and surface, was $10 \mathrm{~mm}$, and a $500 \mathrm{~mm} / \mathrm{min}$ feed was used. This parameter setting was selected as best practise parameter from process tests performed prior to this investigation.

Table 3 summarises the test matrix containing the five different EDM machined samples that were post processed individually.

Fig. 2 Overview of the test sample, a part of an Inconel 718 shaft, showing the post processed positions where the dark areas are the EDM surface

\subsection{Analyses methods}

The test samples were evaluated with different techniques involving residual stress measurements with X-ray diffraction, chemical analysis of the surface with X-ray fluorescence (XRF) and evaluation of the surface topography with interferometric microscopy.

\subsubsection{Residual stresses}

Residual stress measurements were preformed with X-ray diffraction, which is a well-established method to measure residual stresses on the surfaces as well as below the surface. The measurements were performed with a Stresstech G2R XStress 3000 diffractometer equipped with a Manganese X-ray tube $(\lambda 0.21031 \mathrm{~nm})$. The lattice plane (311) was measured which has a $2 \theta$ diffraction peak located at $151.88^{\circ}$. The measurement strategy of the modified $\sin ^{2} \psi$ method was used with 5 psi angles $\left(45^{\circ} \ldots-45^{\circ}\right)$. The residual stresses was calculated using Hook's law, assuming elastic strain theory, with a Young's modulus of 199.9 MPa and 0.29 in Poisson's ratio, further described by Noyan and Cohen [29].

Measurements of residual stress profiles were performed with layer removal, where successive material removal was performed using electro polishing. The electro polishing was

EDM surface

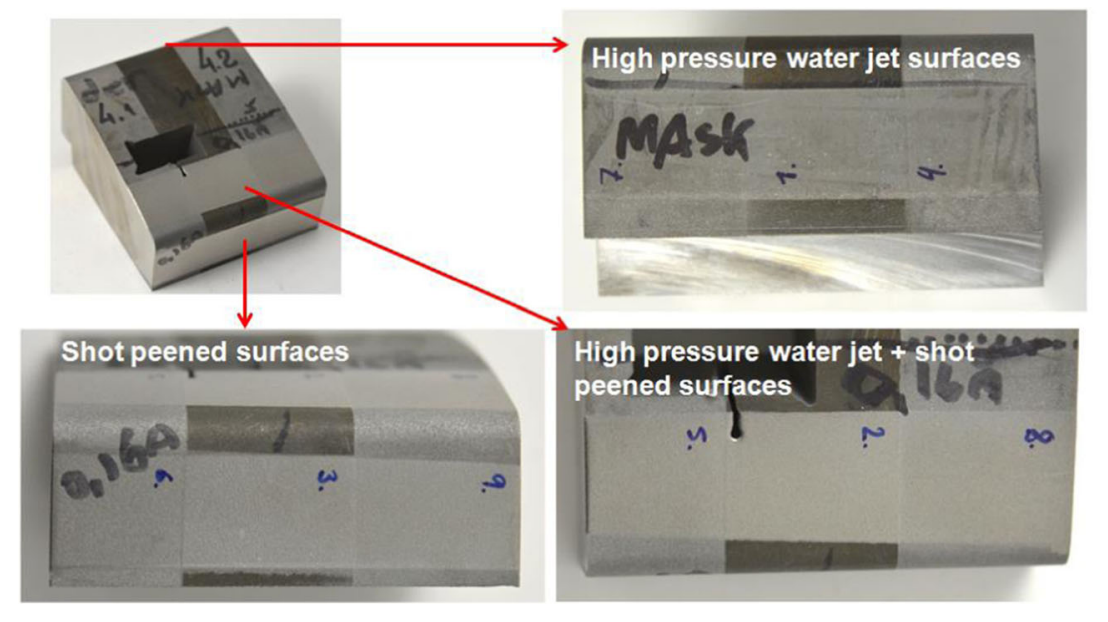


Table 3 Post processing test matrix

\begin{tabular}{llllll}
\hline Sample & Post process & Abbreviation & Process 1 & Process 2 & Process 3 \\
\hline 1 & High pressure Water jet & HPWJ & EDM & HPWJ & \\
2 & Shot peening & SP & EDM & SP & \\
3 & Grit blasting & GB & EDM & GB & \\
4 & High pressure Water jet + & & & & \\
& Shot peening & HPWJ + SP & EDM & HPWJ & SP \\
5 & Grit blasting + shot peening & GB + SP & EDM & GB & SP \\
\hline
\end{tabular}

done with Struers Movipol and Struers electrolyte A2. The diffraction data contains additional information that could be used to study the amount of cold working of the material. The width of the diffraction peak at half maximum, FWHM, is frequently used for this purpose $[30,31]$ and was also employed for evaluation in the present investigations.

\subsubsection{Surface contamination}

The chemical content of the contaminations on the surface was measured with a handheld Thermo Scientific Niton XL3t GOLDD+ X-ray florescence (XRF) equipment in a similar manner as described in [13]. This equipment utilises the characteristic secondary X-rays that emit from a sample surface which is exposed to high-energy X-rays in order to determine the chemical content. This equipment has an expanded range for detecting elements which include magnesium, aluminium, silicon, phosphorous and sulphur. The results from the chemical analysis with XRF are average values from three measurements at different locations for each sample.

A Jeol 7800 0F SEM equipped with a Brucker XFlash 5010 energy-dispersive spectroscopy (EDS) detector was also used for chemical analysis of the surfaces. An EDS-detector measures the electron interaction with the sample and generates energy spectrums that can be translated into chemical information. This chemical analysis was performed in order to identify alumina oxide particles on the surface of the gritblasted sample.

\subsubsection{Surface roughness}

The surface roughness was measured using interferometric microscopy with a Sensofar S Neox instrument. The roughness measurements were performed over a $878 \times$ $659 \mu \mathrm{m}$ surface in the centre of the sample at three different positions with a lateral resolution of $0.258 \mu \mathrm{m}$. The result was filtered using a $5 \times 5$ spatial median denoise filter for the short wavelengths and a robust Gaussian filter for the long wavelengths with nesting index $250 \mu \mathrm{m}$. In this investigation, the average values of different surface topography parameters from three measurements were used to characterise the surface roughness [32].

\section{Results}

\subsection{Surface topography}

The surface roughness has strongly been influenced by the post processes. The results show that the EDM surface, HPWJ surface and the grit-blasted surface are quite rough with many small sharp peaks distributed all over the surface, as shown in Fig. 3. The shot peening process and combinations of shot peening and the two other post processes show a reduced surface roughness compared to the EDM surface, where shot peening indicates that the surface roughness was lowered by more than one third. The combination of processes $\mathrm{GB}+\mathrm{SP}$ and HPWJ + SP indicate that the shot peening determines the final surface roughness. In Fig. 4, the results are expressed in ISO 25178 height parameters, which indicate that the shot peening generates the smoothest surfaces. The standard deviation, stdav, was calculated for the three measurements that were measured for each of the processed surfaces which are presented as the error bars in Fig. 4. The evaluated ISO 25178 parameters all show a similar trend where the HPWJ has the highest roughness and the shot-peened samples show the smoothest surface. The skewness, Ssk, show a negative value for the HPWJ and the grit blasting, which indicates that this surface is composed of one plateau with deep and fine valleys while a positive Ssk value indicates a lot of peaks on a plane.

For each of the different processes, erosion was estimated by measuring the step height between the EDM surface and the post processed surfaces. The calculated step height is the difference between the mean height of a plane in the EDM surface and a mean plane in the post processed surface. The result indicates that HPWJ generated the highest degree of erosion and that grit blasting is almost three fourths lower than the HPWJ erosion. Furthermore, the results show that shot peening almost does not erode the surface at all; see Table 4.

\subsection{Residual stresses}

The shot peening operation generated a residual stress profile with the highest compressive residual stresses both 


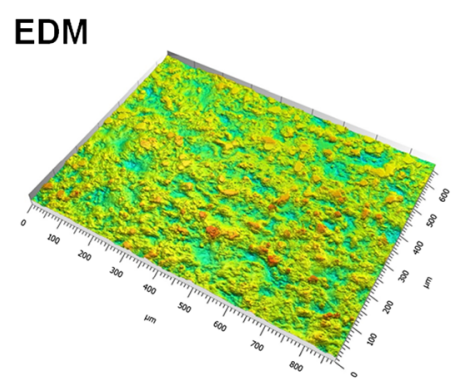

Shot peening

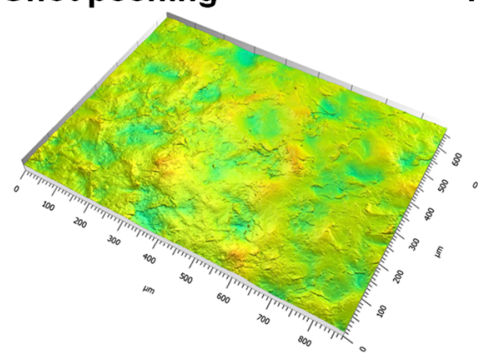

HPWJ

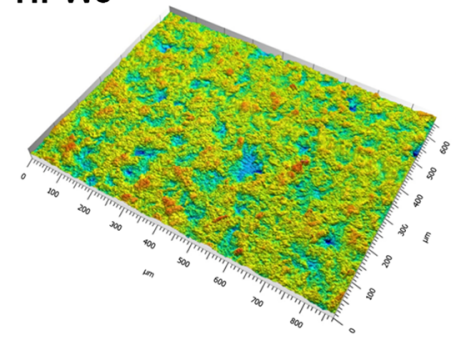

HPWJ+ Shot peening

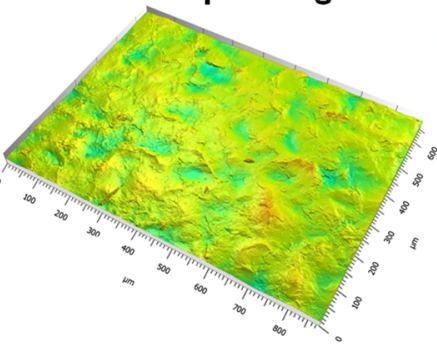

Grit blasting

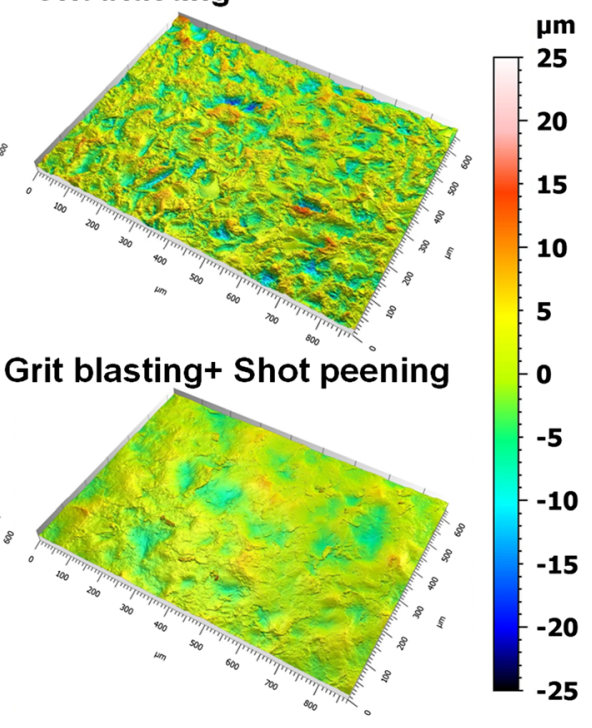

Fig. 3 3D views of the different surfaces from interferometry measurements where the scale bar shows the height profile for the different surfaces

in magnitude and penetration depth, which is more than $300 \mu \mathrm{m}$, according to Fig. 5. Both the grit blasting and high-pressure water jet cleaning also generated a fairly high compressive residual stress profiles with an affected depth of approximately $200 \mu \mathrm{m}$ for grit blasting and $150 \mu \mathrm{m}$ for the HPWJ. It is further observed that the combined post processes of GB $+\mathrm{SP}$ and $\mathrm{HPWJ}+\mathrm{SP}$ show almost identical profiles as the shot-peened sample which indicate that the final SP operation determines the residual stress state.
The full width half maximum, FWHM, profiles derived from the diffraction data are illustrated in Fig. 6. These profiles show similar trends as the residual stress profile, where the shot-peened samples had high-surface FWHM and the greatest affected depth. The grit-blasted sample shows the highest surface FWHM but the affected depth is less than half of the shot-peened samples. Finally, the EDM and HPWJ samples show much lower impact on the FWHM with fairly low FWHM values at the surfaces as well as a low (shallow) depth of impact.
Fig. 4 Surface roughness, Sa, and other selected ISO25178-2 parameters of the different surfaces where the error bars represent the standard deviation from the three measurements for each sample

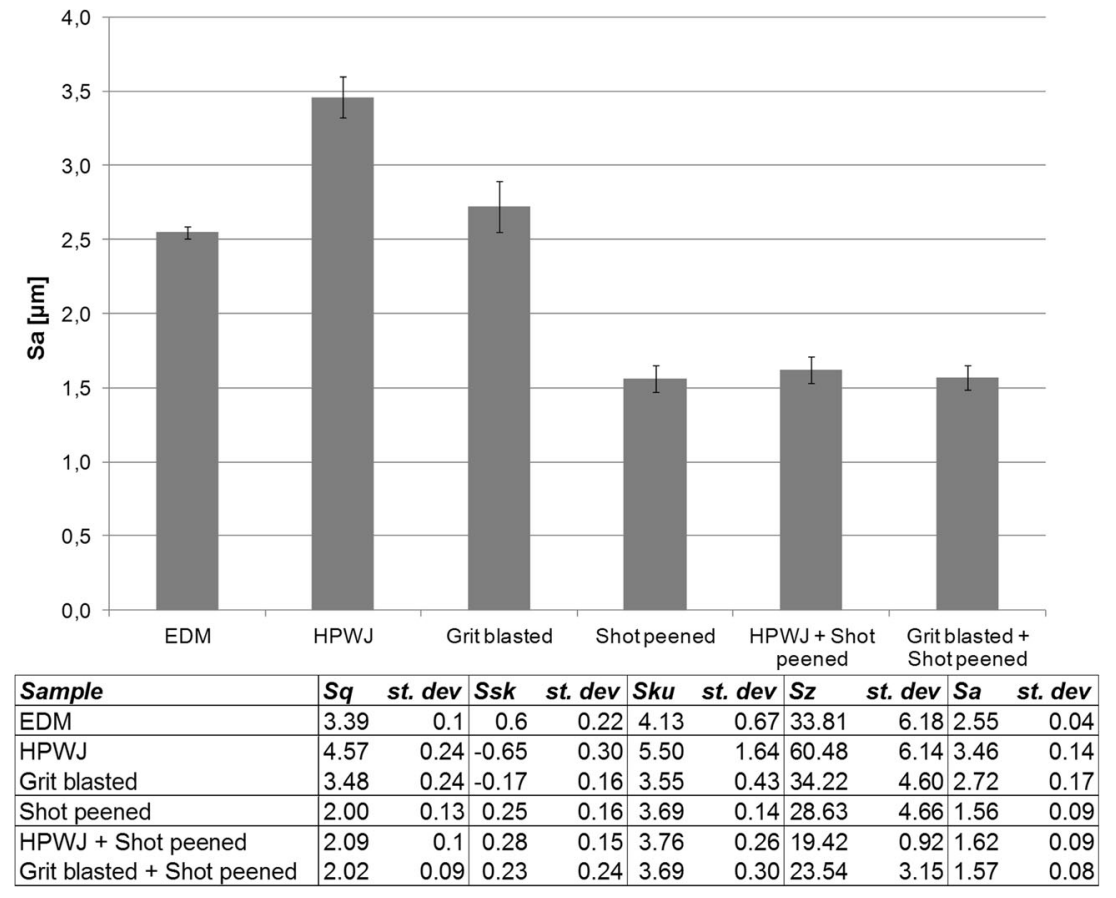


Table 4 Erosion depth estimations from interferometry measurements

\begin{tabular}{lc}
\hline Process & Step height $[\mu \mathrm{m}]$ \\
\hline Shot peening & 6.3 \\
High pressure water jet & 39.1 \\
Grit blasting & 11.3 \\
\hline
\end{tabular}

\subsection{Chemical content}

The measurements of the amount of EDM wire residue with XRF show that the HPWJ-treated surfaces exhibit the lowest amounts of zinc, and for copper, no content at all was detected (see table in Fig. 7). This implies that HPWJ has the greatest ability to remove RCL of the compared post processes. Grit blasting does also remove the re-cast layer quite well but not to the low levels as HPWJ. The shot-peened surface shows only a moderate reduction of the $\mathrm{Zn}$ and $\mathrm{Cu}$ content, and the amounts detected are still fairly high. This implies that the shot peening process only removes a limited amount of the re-cast layer. However, if the shot peening is preceded by either grit blasting or HPWJ, the surface shows much better results with low amounts of $\mathrm{Zn}$ and $\mathrm{Cu}$.

\subsection{Microstructure}

The microstructure was analysed using scanning electron microscopy with the results shown in Fig. 8 . The microstructure of the surface was analysed in $\times 2000$ magnification in order to investigate the presence and depth of the re-cast layer. The result indicates great difference in how the surface was affected by the different post processes.

\subsubsection{Electrical discharge machining}

The EDM surface shows clear traces of discontinuous re-cast layer as a zone of darker discontinuous layer containing a mix of the base material with spherically shaped pores. The re-cast layer was rather uneven and an extension into the material in the interval 1-20 $\mu \mathrm{m}$ was measured.

\subsubsection{High-pressure water jet}

The HPWJ surface shows no traces of RCL on the surface, and the uneven surface does not seem to be deformed. However, the post processed surface contains quite rough peaks and valleys. The surface also contains smaller column-shaped holes.

\subsubsection{Grit blasted}

The grit-blasted (GB) surfaces indicate quite high amounts of residues from the grit-blasting medium in the very outer surface. The uneven surface indicates a quite high degree of deformation. Chemical analysis using EDS of the grit-blasted surface confirmed that the black spots in the outer surface are alumina oxide particles from the grit-blasting medium.

\subsubsection{Shot peened}

The shot-peened (SP) surfaces show a quite high presence of RCL and also a high degree of deformation where the outer surface is rather flat and deformed by the shot-peened media. Moreover, these surfaces show lamellar surface cracks located along the surface to a depth of less than $5 \mu \mathrm{m}$. The cracks appear only in the RCL layer and preferably located along the surface.
Fig. 5 Residual stress profile measurements with XRD of the different surfaces; the error bars represent the calculated error for the peak fitting of the diffraction data

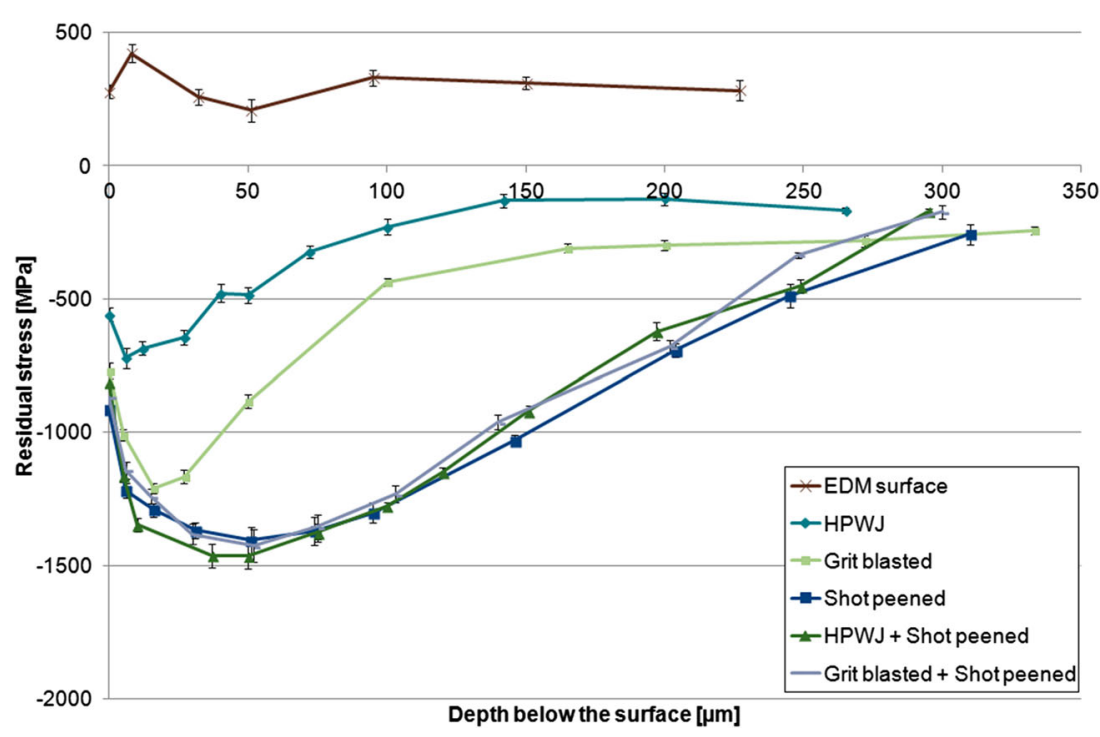


Fig. 6 Full width half maximum (FWHM) profiles with XRD of the different post processed surfaces

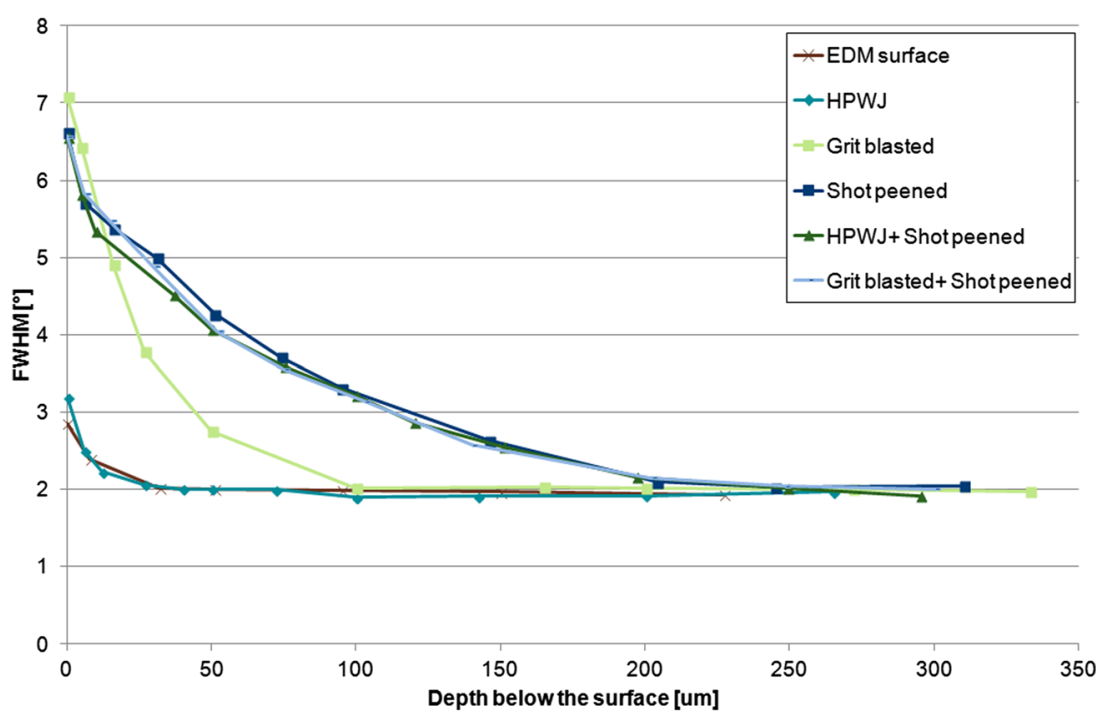

\subsubsection{Combined post processes}

The surface generated by the combined post processes GB + SP shows residues of the grit-blasting media in the outer surface region and a much flatter surface compared to the solely grit-blasted sample.

The HPWJ + SP surface shows that the HWPJ process removed the RCL and that the SP operation flattened the surface. However, these surfaces show rather large cracks initiated along the surface, which are extended in a direction across the surface. This pattern across the surface is a significant difference compared to the cracks detected in the shotpeened samples that appeared as lamellar cracks only along the surface.
The cracks found in the surface generated by the combined processes HPWJ + SP are extended quite far into the material. The example in Fig. 8 exhibited the deepest observed crack with an extension of roughly $25-30 \mu \mathrm{m}$ into the surface.

\section{Analysis and discussion}

The EDM process generates a relatively smooth surface that contains discontinuous islands of RCL. The initial residual stress state of the EDM shaft shows quite high tensile residual stresses surprisingly deep below the surface. Even at depths of $200 \mu \mathrm{m}$, the stresses are tensile. Even though this result is unexpectedly high, similar results were reported by Chen
Fig. 7 XRF measurements of the $\mathrm{Zn}$ and $\mathrm{Cu}$ content on the surface of the different samples where the error bars represent the standard deviation from the three measurements for each sample

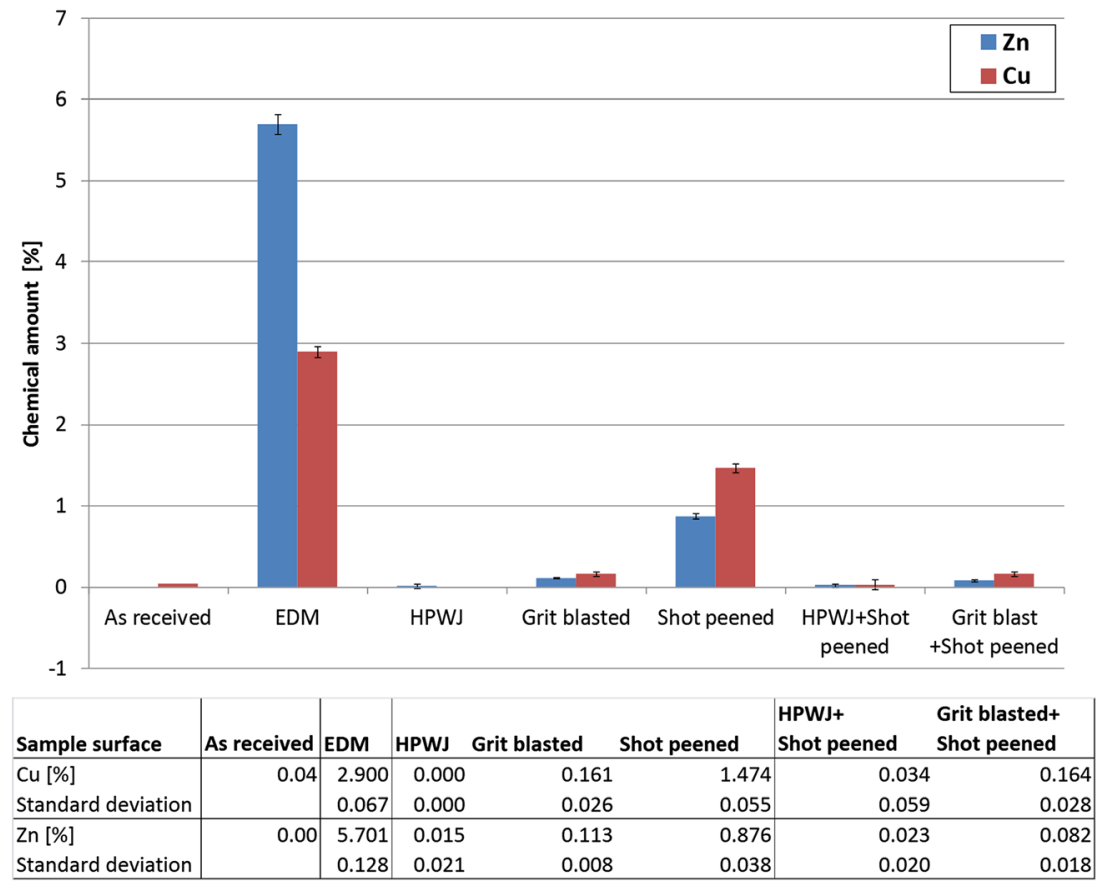



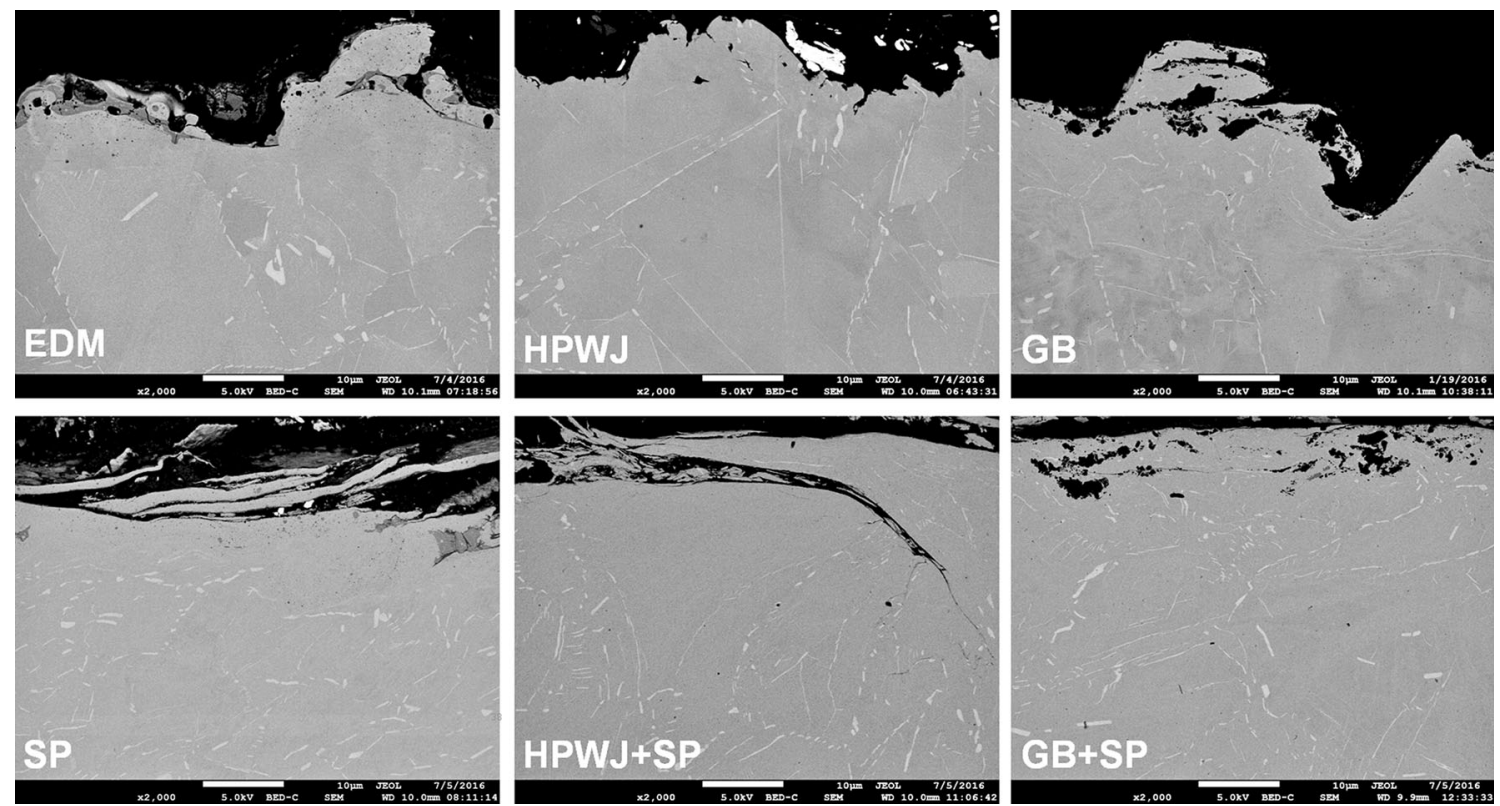

Fig. 8 Microstructures of the different samples from SEM images in $\times 2000$ magnification

et al. who performed fatigue testing on forged and heat-treated EDM:ed coupons of Inconel 718 [27]. In that study, the residual stresses after EDM were at levels around $400 \mathrm{MPa}$ and the fatigue testing showed a decreased fatigue life with $30 \%$. However, the influence of the EDM process is only limited to the outermost layer of approximately $50 \mu \mathrm{m}$ while the residual stress state from the casting or forging of the shaft most likely generated the high tensile stress state that was measured at greater depths. This rather high tensile residual stress state is to be avoided, but in this investigation, the RCL removal capabilities are of interest, as well as how the surface state was affected by the post processing.

However, in order to recover the surface integrity for an EDM process, the issue regarding the RCL residue contents as well as the tensile residual stress state and roughness need to be addressed.

\subsection{Ability for re-cast layer removal}

Regarding the cleaning performance of the different post processes, an evaluation method using XRF to detect the presence of RCL was used. This method has been shown to describe the amount of residue in the surface from the EDM process very accurately [23]. The results show that the HPWJ process is the most capable process that completely removes the RCL. Grit blasting also shows quite good capabilities for removing the RCL but not to the same extent as HPWJ. In this evaluation, it was further observed that shot peening only had a very limited ability to remove RCL. A major part of being able to compare and determine the different post processes' ability of cleaning the surface is the utilisation of chemical analysis of the surface. There are reports in the literature where energy- dispersive spectroscopy (EDS) has been used in order to identify the presence of EDM wire residues in the EDM:ed surface $[33,34]$ but no similar results reported where an XRF has been used to relatively quantify the amount and thereby allowing comparisons between different post processed surfaces. The main advantages would be that simpler and non-destructive equipment could be used in normal environment, in comparison to EDS where vacuum is required. The results in this investigation could be considered as complementary investigations to the prior results showing that this method is a very useful tool when determining how well the surface has been cleaned from the different post processes.

\subsection{Re-cast layer removal by erosion}

The reason for the difference in RCL removal for the three different processes is that HPWJ and grit blasting (GB) utilise erosion rather than just deforming the surface which is the case of shot peening. The influence of the erosion could be observed in the topography data where the HPWJ increased the roughness compared to the original EDM surface. This hydrodynamic erosion that occurs when the high-pressure water jet beam strikes the surface is greatly dependent on the water pressure. This was further described by Taylor [14] who showed that the erosion and surface roughness depends on the water jet pressure where an increased pressure resulted in higher erosion and surface roughness.

Another type of erosion occurs for grit blasting, which takes advantage of the rough abrasive grit particles that strike the surface and spall of material from the exposed surface layer. The amount of erosion that occurs is influenced by the type of media and exposure time. Prior work performed on the 
same sample evaluated the influence of exposure time and is presented in [23]. This showed an almost linear increase of the erosion with exposure time. A comparative investigation performed by Lieblich et al. [19] showed that grit blasting generated a lower surface roughness compared to AWJ which is in agreement with the results retrieved in the present investigation. It was further reported that the mass loss, erosion, of AWJ was more than double grit blasting which also correlates well with the results in the present investigation. The measured erosion from the present study showed that the step height, erosion, between an EDM surface and the HPWJ surface resulted in more than three times the volumetric erosion compared to grit blasting and six times greater than the shotpeened surface.

\subsection{Effects on the microstructure}

The influence on the microstructure further revealed information of how the different post processes have affected the surface integrity. Most importantly, it was observed that the shot-peened surface showed lamellar cracks oriented along the surface at a depth of 20-30 $\mu \mathrm{m}$.

The lamellar cracks indicate that the built-up pressure from the shot peening, the Hertzian pressure, was too high for this material and resulted in cracking, especially when considering the relatively large change from a high-tensile residual stress state that the shaft had before the post processing into a high compressive residual stress state.

Investigating the cross sections also showed a potential risk that the EDM process creates a relatively rough original surface with discontinuous peaks of both the core material and RCL. Depending on the height of these peaks and how they deform, there is a risk that this material folds onto the surface without any bonding and appears as cracks, also known as tears and laps. This will also result in a risk that possible particles or unwanted residues on the surface will be embedded into the surface by the following deformation caused by shot peening that makes the surface flat. Comparing the grit-blasted surface microstructure to the HPJW surface clearly shows that the HPWJ surface is totally free of RCL while the grit-blasted (GB) surface shows minor traces of RCL and abrasive particles embedded into the rough surface peaks.

Further analysis of the cracks showed that all of them are initiated only in the outer RCL layer, implying that the brittle RCL layer has cracked due to the pressure overload from the shot peening process. It seems that even though the cracks have initiated in the outer layer, they could eventually propagate into the material as in the case for the combined post processes' surface of HPWJ + SP. These results imply that non-destructive testing using dye penetrant testing would be important to consider for future work.

\subsection{Effects on the surface roughness}

This investigation has demonstrated that shot peening (SP) cannot be considered as an alternative to both remove RCL and to create a smooth surface. The results clearly show that shot peening only removes a very limited amount of RCL but manages to create a smoothening of the surface. The topography measurements show that shot peening lowered the surface roughness with more than $35 \%$, resulting in a surface roughness of about $1.5 \mu \mathrm{m}$. Further improvements of the surface roughness could probably be achieved if an even smaller diameter of the shot peening media is to be selected. This is in parity with the results reported by Zaleski et al. who investigated the influence of impact energy and shot size [35].

The samples that were post processed using a combined process of a cleaning operation as well as a shot peening operation show that the surface is free from RCL and that the surface roughness is governed by the subsequent shot peening operation. However, the sample with the combined grit and shot blasting shows traces of embedded grit-blasting medium in the outer surface, which is unwanted. The combined HPWJ and shot-peened sample on the other hand shows cracks in the surface most likely because of a combined impact from the transformation from high tensile stresses into high compressive stresses generated by two different coldworking methods.

\subsection{Effects on the residual stress state}

Concerning the influence on the residual stresses, all three post processes showed ability to generate quite high compressive residual stresses with relatively large penetration depth. Shot peening proved to be superior at generating high compressive residual stresses of almost $-1400 \mathrm{MPa}$ at a depth of $50 \mu \mathrm{m}$. This is similar to results reported by others showing a high compressive stress level. For example, Bhowal et al. reported of compressive stresses after shot peening of Inconel 718 of approximately $-1200 \mathrm{MPa}$ which improved the fatigue strength 5-10 times the one of a machined surface with tensile residual stresses [36]. Such high compressive residual stresses are desirable from a fatigue perspective and were further reported by Chen et al. who showed that shot peening of Inconel 718 greatly influences the surface performance and increases the fatigue limits by introducing high compressive residual stresses [27].

Further, it could be observed that the impact from the shot peening also governs the residual stress state for the two combined post processes. The difference between the FWHM profiles shows very interesting results. According to literature [20], FWHM can be used as an assessment of the amount of cold working. The results from this investigation show that the amount of cold working differs a lot between the different post 
processes. This shows a similar trend as for the residual stress profiles in the present study where the shot-peened samples generated the greatest work hardening.

It could also be seen that the grit blasting has generated the highest amount of cold work but to a lower penetration depth compared to the shot peened samples.

Finally, the HPWJ and EDM FWHM profiles show the least amount of cold work and to a fairly low penetration depth of only $30 \mu \mathrm{m}$. This result indicates that the deformations from the HPWJ processes are superficial while the residual stress is affected at greater depths.

\section{Conclusions}

The result from this investigation implies the importance of performing a thorough surface integrity evaluation, both before and after processing the material.

With such information, it is possible to understand the outcome from machining and how to select an appropriate post process, or processes, to recover the surface integrity. The following conclusions could be drawn:

- A combination of two post processes is required in order to recover the surface integrity after EDM processing that generates a surface with discontinuous islands of RCL.

- The HPWJ surface show the largest amount of removal of EDM wire residue, indicating the highest degree of cleaning performance closely followed by grit blasting.

- Grit blasting erodes the surface but abrasive particles will be embedded into the surface.

- The three investigated post processes grit blasting, high pressure water jet and shot peening generate compressive residual stresses in the surface region.

- Shot peening generates the highest amounts of compressive residual stresses but has a limited capability for removing RCL.

- Grit blasting and HPWJ cause a roughening of the surface topography while shot peening generates a smoother surface.

- Investigating the residual stress state before post processing is required when selecting the shot peening parameters. The total impact energy onto the surface from the different process steps needs to be evaluated in order to avoid initiation of cracks.

Acknowledgments The results presented in this paper are part of the research project G5Demo-2 and financed by VINNOVA, the Swedish government agency within Ministry of Enterprise. Special thanks are due to GKN for supplying test materials, information and expertise in the involved processes. The authors also would like to acknowledge the KK-foundation and the SiCoMaP research school.
Open Access This article is distributed under the terms of the Creative Commons Attribution 4.0 International License (http:// creativecommons.org/licenses/by/4.0/), which permits unrestricted use, distribution, and reproduction in any medium, provided you give appropriate credit to the original author(s) and the source, provide a link to the Creative Commons license, and indicate if changes were made.

\section{References}

1. EEA (2016) European aviation environmental report 2016. European Aviation Safety Agency. https://doi.org/10.2822/385503

2. Zhang Y, Zhang D, Wu B (2015) An approach for machining allowance optimization of complex parts with integrated structure. $\mathrm{J}$ Comput Des Eng 2(4):248-252. https://doi.org/10.1016/j.jcde. 2015.06.007

3. Sun Y, Xu J, Guo D, Jia Z (2009) A unified localization approach for machining allowance optimization of complex curved surfaces. Precis Eng 33(4):516-523. https://doi.org/10.1016/j.precisioneng. 2009.02.003

4. Ezugwu EO, Bonney J, Fadare DA, Sales WF (2005) Machining of nickel-base, Inconel 718, alloy with ceramic tools under finishing conditions with various coolant supply pressures. J Mater Process Technol 162:609-614. https://doi.org/10.1016/j.jmatprotec.2005. 02.144

5. Ezugwu E, Bonney J, Yamane Y (2003) An overview of the machinability of aeroengine alloys. J Mater Process Technol 134(2): 233-253. https://doi.org/10.1016/S0924-0136(02)01042-7

6. Alagan NT, Beno T, Wretland A (2016) Investigation of modified cutting insert with forced coolant application in machining of alloy 718. Procedia CIRP 42:481-486. https://doi.org/10.1016/j.procir. 2016.02.236

7. Ho K, Newman S (2003) State of the art electrical discharge machining (EDM). Int J Mach Tools Manuf 43(13):1287-1300. https://doi.org/10.1016/S0890-6955(03)00162-7

8. Kumar S, Singh R, Singh TP, Sethi BL (2009) Surface modification by electrical discharge machining: a review. J Mater Process Technol 209(8):3675-3687. https://doi.org/10.1016/j.jmatprotec. 2008.09.032

9. Kruth J-P, Stevens L, Froyen L, Lauwers B (1995) Study of the white layer of a surface machined by die-sinking electro-discharge machining. CIRP Ann 44(1):169-172. https://doi.org/10.1016/ S0007-8506(07)62299-9

10. Sandvik Coromant (ed) (2010) Technical guide — cutting processes, 2nd edn. Sandvik Coromant, Sandviken

11. Elbestawi MA, Ismail F, Yuen KM (1994) Surface topography characterization in finish milling. Int J Mach Tools Manuf 34(2): 245-255. https://doi.org/10.1016/0890-6955(94)90104-X

12. Bouzid Saï W, Ben Salah N, Lebrun JL (2001) Influence of machining by finishing milling on surface characteristics. Int $J$ Mach Tools Manuf 41(3):443-450. https://doi.org/10.1016/S08906955(00)00069-9

13. Guha A, Barron RM, Balachandar R (2011) An experimental and numerical study of water jet cleaning process. J Mater Process Technol 211(4):610-618. https://doi.org/10.1016/j.jmatprotec. 2010.11.017

14. Taylor TA (1995) Surface roughening of metallic substrates by high pressure pure waterjet. Surf Coat Technol 76-77(Part 1):95-100. https://doi.org/10.1016/0257-8972(95)02528-6

15. Deam RT, Lemma E, Ahmed DH (2004) Modelling of the abrasive water jet cutting process. Wear 257(9-10):877-891. https://doi.org/ 10.1016/j.wear.2004.04.002 
16. Wang J (2009) Particle velocity models for ultra-high pressure abrasive waterjets. J Mater Process Technol 209(9):4573-4577. https:// doi.org/10.1016/j.jmatprotec.2008.10.021

17. Escobar-Palafox GA, Gault RS, Ridgway K (2012) Characterisation of abrasive water-jet process for pocket milling in Inconel 718. Procedia CIRP 1:404-408. https://doi.org/10.1016/ j.procir.2012.04.072

18. Barriuso S, Lieblich M, Multigner M, Etxeberria I, Alberdi A, González-Carrasco JL (2011) Roughening of metallic biomaterials by abrasiveless waterjet peening: characterization and viability. Wear 270(9-10):634-639. https://doi.org/10.1016/j.wear.2011.01. 024

19. Lieblich M, Barriuso S, Ibáñez J, Ruiz-de-Lara L, Díaz M, Ocaña JL, Alberdi A, González-Carrasco JL (2016) On the fatigue behavior of medical Ti6Al4V roughened by grit blasting and abrasiveless waterjet peening. J Mech Behav Biomed Mater 63:390-398. https://doi.org/10.1016/j.jmbbm.2016.07.011

20. Sadasivam B, Arola D (2012) An examination of abrasive waterjet peening with elastic pre-stress and the effects of boundary conditions. Mach Sci Technol 16(1):71-95. https://doi.org/10.1080/ 10910344.2012.648565

21. Huang L, Kinnell P, Shipway PH (2013) Parametric effects on grit embedment and surface morphology in an innovative hybrid waterjet cleaning process for alpha case removal from titanium alloys. Procedia CIRP 6:594-599. https://doi.org/10.1016/j.procir. 2013.03.077

22. Khan AA, Al Kheraif AA, Alhijji SM, Matinlinna JP (2016) Effect of grit-blasting air pressure on adhesion strength of resin to titanium. Int J Adhes Adhes 65:41-46. https://doi.org/10.1016/j. ijadhadh.2015.11.003

23. Holmberg J, Wretland A, Berglund J (2016) Grit blasting for removal of recast layer from EDM process on Inconel 718 shaft: an evaluation of surface integrity. J Mater Eng Perform 25(12):5540 5550. https://doi.org/10.1007/s11665-016-2406-8

24. Champaigne J (2001) Shot peening overview. www.shotpeener. com

25. Totten G, Howes M, Inoue T (2002) Handbook of residual stresses and deformation of steel. 1st edn. ASM International. Materials Park, Ohio 44073-0002
26. Koster WP, Gatto LR, Cammett JT (1981) Influence of shot peening on surface integrity of some machined aerospace materials. 1st International Conference on Shot Peening 287-295

27. Chen Z (2017) Surface integrity and fatigue performance of nickelbased superalloys. Thesis https://doi.org/10.3384/diss.diva-134124

28. Khadhraoui M, Cao W, Castex L, Guédou JY (1997) Experimental investigations and modelling of relaxation behaviour of shot peening residual stresses at high temperature for nickel base superalloys. Mater Sci Technol 13(4):360-367. https://doi.org/10.1179/ mst.1997.13.4.360

29. Noyan IC, Cohen JB (1987) Residual stress measurement by diffraction and interpretation, 1987th edn. Springer-Verlag New York Inc., New York

30. Fernández Pariente I, Guagliano M (2008) About the role of residual stresses and surface work hardening on fatigue $\Delta \mathrm{K}$ th of a nitrided and shot peened low-alloy steel. Surf Coat Technol 202(13): 3072-3080. https://doi.org/10.1016/j.surfcoat.2007.11.015

31. Matlock BS, Snoha DJ, Grendahl SM (2009) Using XRD elastic and plastic strain data to evaluate the effectiveness of different coldworking techniques in aerospace materials. Powder Diffract 24(S1): 51-58. https://doi.org/10.1154/1.3133148

32. International Organisation for Standarization (2012) ISO 25178-2: 2012, Geometrical product specifications (GPS) - surface texture: areal-part 2: terms, definitions and surface texture parameters, 25178-2:2012

33. Newton TR, Melkote SN, Watkins TR, Trejo RM, Reister L (2009) Investigation of the effect of process parameters on the formation and characteristics of recast layer in wire-EDM of Inconel 718. Mater Sci Eng A 513-514:208-215. https://doi.org/10.1016/j. msea.2009.01.061

34. Li L, Guo YB, Wei XT, Li W (2013) Surface integrity characteristics in wire-EDM of Inconel 718 at different discharge energy. Procedia CIRP 6:220-225. https://doi.org/10.1016/j.procir.2013. 03.046

35. Zaleski K, Skoczylas A, Brzozowska M (2017) The effect of the conditions of shot peening the Inconel 718 nickel alloy on the geometrical structure of the surface. Adv Sci Technol Res J 11(2): 205-211. 10.12913/22998624/74180

36. Bhowal P, Stoltz D, Wusatowska-Sarnek AM, Montero R (2008) Surface effects on low cycle fatigue behavior in IN 718 alloy. Conference superalloys 2008 417-423 